\title{
Early evaluation of the aortic root after Nicks' procedure
}

Ujjwal Kumar Chowdhury, MCh, Diplomate NB, Sukhjeet Singh, MCh, Niwin George, MCh, Suruchi Hasija, DM, Lakshmikumari Sankhyan, MCh, Niraj Nirmal Pandey, DM, Sanjoy Sengupta, Diplomate, MCh, and Mani Kalaivani, PhD

\section{ABSTRACT}

Objective(s): To determine the influence of surgical techniques adopted to avoid suture line disruption, periprosthetic leakage, patch dislodgement, pericardial patch aneurysm formation, and the long-term stability of aortic root enlargement (ARE) during aortic valve replacement (AVR).

Methods: One hundred fifteen patients undergoing AVR or combined aortic and mitral valve replacements with Nicks' posterior ARE between 1997 and 2019 underwent long-term echocardiographic and angio-computed tomographic evaluation. Age was 11-72 years (AVR: median, 30; interquartile range, 21-47 years; AVR and mitral valve replacement: median, 27.5; interquartile range, 20-37.5 years). The aortotomy was closed using autologous pericardial patch and Teflon-buttressed sutures.

Results: Hospital mortality was $1.7 \%(n=2)$, with $4(3.5 \%)$ late deaths. At a mean follow-up of $123.11 \pm 77.67$ months, the survival probability from Kaplan-Meier was $93.25 \pm 0.03 \%$. No cases of severe prosthesis-patient mismatch (PPM) were observed, and only 2 patients had moderate PPM. Median aortic root diameters at the level of sinus of Valsalva and sinotubular junction were 32 (29-35) $\mathrm{mm}$ and 33 (30-36) mm, respectively, at discharge, and were 33 (30-36) mm, and 33 (31-37) $\mathrm{mm}$, respectively, at latest follow-up, with no cases of late pericardial patch aneurysm.

Conclusions: ARE is a safe adjunct to AVR in patients with a small aortic annulus to prevent PPM. Retention of a pericardial collar and Teflon-buttressed sutures is an expedient, safe, and effective technique in reducing bleeding at the enlarged ventriculo-aortic junction. Autologous pericardial patch aortoplasty is not associated with late aneurysm/pseudoaneurysm formation. (JTCVS Techniques 2020;4:85-96)

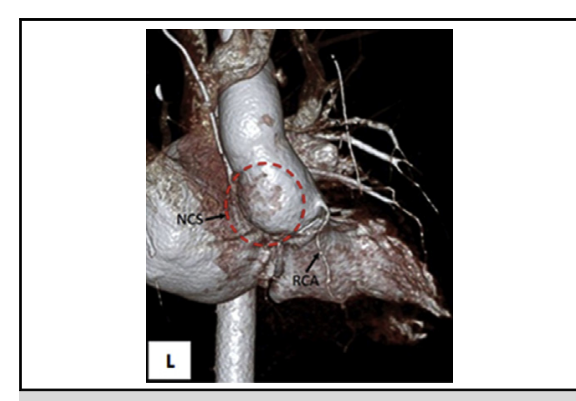

Postoperative CT angiography showing the dilated nonaneurysmal aortic root.

\section{CENTRAL MESSAGE}

Retention of the autologous pericardial collar and Teflonbuttressed suture is associated with a very low incidence of bleeding at the annular enlargement site in Nicks' procedure.

\section{PERSPECTIVE}

Retention of an autologous pericardial collar and Teflon buttressed suturing of the ventriculoaortic junction is associated with reduced bleeding and no late aneurysm or pseudoaneurysm formation of the aortic root.

See Commentaries on pages 97 and 99.
Video clip is available online.

\footnotetext{
From the Cardiothoracic Sciences Centre, All India Institute of Medical Sciences, New Delhi, India.

Received for publication July 29, 2020; revisions received July 29, 2020; accepted for publication Aug 10, 2020; available ahead of print Aug 13, 2020.

Address for reprints: Ujjwal Kumar Chowdhury, MCh, Diplomate NB, Department of Cardiothoracic and Vascular Surgery AIIMS, New Delhi 110029, India (E-mail: ujjwalchow@rediffmail.com or ujjwalchowdhury@gmail.com).

2666-2507

Copyright $(C 2020$ The Authors. Published by Elsevier Inc. on behalf of The American Association for Thoracic Surgery. This is an open access article under the CC BY-NCND license (http://creativecommons.org/licenses/by-nc-nd/4.0/).

https://doi.org/10.1016/j.xjtc.2020.08.017
}

Despite the availability of advanced prosthetic valve models, aortic root enlargement (ARE) may be required during aortic valve replacement (AVR) to insert an adequate-sized prosthesis and avoid prosthesis-patient mismatch (PPM). ${ }^{1}$ Children and teenagers with a small aortic annulus may require ARE to delay a redo AVR after physical growth has occurred. This also includes potential candidates for a transcatheter AVR. ${ }^{2,3}$

Studies have reported that PPM is associated with unstable hemodynamics and greater mortality after AVR. ${ }^{4-6}$ To minimize the incidence of PPM as indexed orifice area of $<0.85 \mathrm{~cm}^{2} / \mathrm{m}^{2}$, we chose to perform Nicks' posterior ARE when the debrided annulus could not admit a stented prosthesis based on patient's body size. ${ }^{4}$

The posterior ARE technique described by Nicks and associates $^{7}$ and Manouguian and Seybold-Epting ${ }^{8}$ is a 


\section{Abbreviations and Acronyms \\ ARE = aortic root enlargement \\ AVR $=$ aortic valve replacement \\ $\mathrm{iEOA}=$ indexed effective orifice area \\ $\mathrm{LV}=$ left ventricle \\ $\mathrm{LVEF}=$ left ventricular ejection fraction \\ LVOT $=$ left ventricular outflow tract \\ MVR $=$ mitral valve replacement \\ PPM = prosthesis-patient mismatch \\ $\mathrm{SD}=$ standard deviation}

technically straightforward procedure. The choice between Nicks' and Manouguian's enlargement depends on the degree of widening required and on the type of aortotomy preferred by the surgeon. A single extension of the oblique horse-shoe shaped aortotomy (Nicks' procedure) widens the aortic root by 5 to $10 \mathrm{~mm}$, thus enabling the surgeon to implant one-size larger prosthesis. An extension of the transverse approach, as described by Manouguian, allows 10 to $15 \mathrm{~mm}$ ARE. $^{7,8}$ Kinsley $^{9}$ described a further conservative method of ARE in 1977 where the incision, 0.5 to $1 \mathrm{~cm}$ in length, was made just anterior to the insertion of medial commissure of the mitral valve into the ventricular septum, thus avoiding injury to mitral valve.

A variety of materials have been used to repair the aortotomy during AVR, including synthetic patches of Dacron, polytetrafluoroethylene, homograft aortic and pulmonary artery, CorMatrix extracellular matrix (CorMatrix Cardiovascular Inc, Roswell, Ga), autologous, and bovine pericardial patches. ${ }^{6-14}$ The concerns of ARE prolonged bypass and ischemia times, subannular bleeding, paraprosthetic leakage due to tearing out of sutures in the area of patch or by omitting pledgets to support the mattress sutures, restricted leaflet motion, especially with the St Jude Regent model due to the subvalvular muscular shelf of left ventricular outflow tract (LVOT), iatrogenic mitral regurgitation, aortic dissection, patch aneurysm, and patch dislodgement. ${ }^{9-14}$

Despite their use for the past 4 decades and scattered reports of complications enunciated previously, scant information is available about the long-term changes in aortic root dimensions and dilatation of pericardial patches. ${ }^{15,16} \mathrm{To}$ address these concerns, the corresponding author has been retaining a pericardial collar at the site of enlarged ventriculoaortic junction and Teflon-buttressed monofilament polypropylene sutures to avoid suture line disruption, thus ensuring perfect hemostasis (Figure 1). ${ }^{17}$ The primary aim of the study was to assess the influence of the surgical technique adopted to avoid suture line disruption, paraprosthetic leakage, aortic dissection, and patch dislodgement.

The secondary objectives of this long-term retrospective study were to assess: (1) the stability of the enlarged aortic annulus over time; (2) the occurrence of pericardial patch aneurysm formation by means of echocardiographic and angio-computed tomography studies; (3) the incidence of cardiac reoperations; and (4) risk factors associated with mortality and morbidity.

\section{METHODS}

This retrospective study conforms to the principles outlined in the Declaration of Helsinki and was approved by the institutional ethics committee. Patients were enrolled in the study protocol after obtaining informed written consent from patients/parents/guardians.

\section{Patient Selection Criteria}

This descriptive case series included patients undergoing isolated AVR, AVR and mitral valve replacements (MVRs), concomitant tricuspid valve repair, and atrial septal defect closure with small aortic annulus requiring posterior ARE of the technique described by Nicks and associates.

Patients requiring ARE, by definition, had inappropriately small annular dimensions per body surface area but were enlarged to achieve an indexed effective orifice area (iEOA) $\geq 0.85 \mathrm{~cm}^{2} / \mathrm{m}^{2}$. Patients undergoing Manouguian's procedure, Konno-Rastan procedure, aortic dissection/ aneurysm repair, or composite aortic root reconstruction were excluded.

Between January 1997 and December 2019, 657 patients underwent isolated mechanical or bioprosthetic AVR, and 754 patients underwent combined AVR and MVR. Concomitant posterior ARE (Nicks) was performed by the corresponding author at All India Institute of Medical Sciences, New Delhi, India, in 115 patients (71 male), and they form the basis of this communication, representing the entire subset of patients having ARE performed during this time interval.

The records of these patients were reviewed for demographic, operative and perioperative features, follow-up echocardiographic, and angiocomputed tomographic studies according to the guidelines and definitions of Society of Thoracic Surgeons database. ${ }^{18}$

In this study population, $78(67.8 \%)$ patients underwent standard Nicks' procedure of ARE and $37(32.2 \%)$ patients underwent modified Nicks' procedure on an individualized basis. ${ }^{7,9,17,19}$ The technical details of both techniques have been addressed in our previous publications. ${ }^{17,19}$ The most significant preoperative patient characteristics are summarized in Table 1.

\section{Echocardiographic Studies and Measurements}

Preoperative studies were performed within 7 days before surgery. Their preoperative and postoperative records were reviewed. Echocardiographic studies were performed at the time of discharge and during follow-up (Philips iE33 echo machine; Philips X7-2T probe, Bothell, Wash). Postoperative evaluation consisted of 3-month clinical examination, electrocardiogram, chest radiograph, cine fluoroscopy, echocardiography, and computed-tomographic angiography. The functional class at follow-up was noted. All patients received warfarin and aspirin $(100 \mathrm{mg} / \mathrm{d})$ for anticoagulation to maintain an international normalized ratio between 2.5 and 3.5.

All long-term survivors were examined and studied between January 2018 and December 2019, which was the closing interval of the study. They underwent a transthoracic 2-dimensional echocardiographic examination by the same team of echocardiographers to verify the stability of the repair, peak and mean transprosthetic gradients, effective orifice area, left ventricular ejection fraction (LVEF), left ventricular (LV) diameters, LV volumes, and degree of LV hypertrophy by means of the LV septal thickness.

Paired $t$ test was used to compare the aortic valve annular diameter, and signed-rank test was used to compare aortic root diameter at sinus of Valsalva and sinotubular junction between the preoperative value and values at time of discharge and at late follow-up. The occurrence of PPM was graded as mild when the iEOA was $\geq 0.85 \mathrm{~cm}^{2} / \mathrm{m}^{2}$, moderate when the iEOA was between $0.85 \mathrm{~cm}^{2} / \mathrm{m}^{2}$ and $0.65 \mathrm{~cm}^{2} / \mathrm{m}^{2}$, and severe when 


\section{Early evaluation of the aortic root after Nick's procedure}
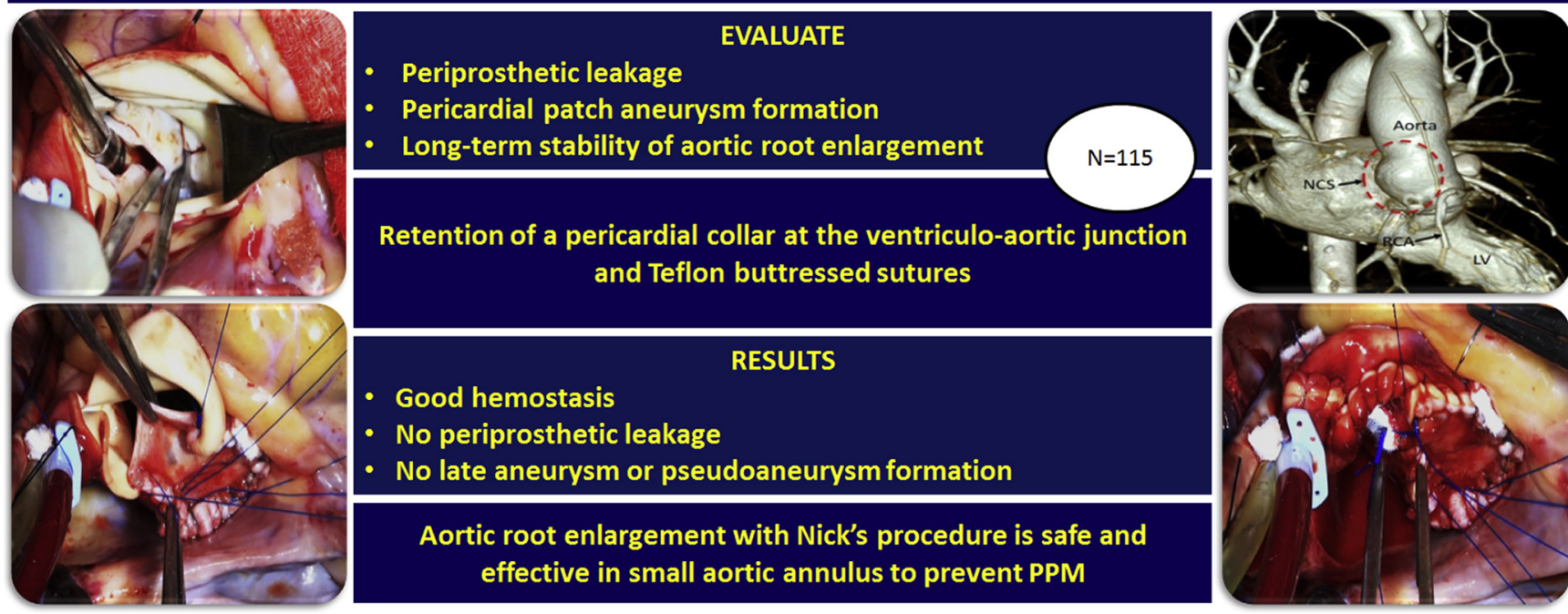

FIGURE 1. Graphic display $(\mathrm{n}=115)$ showing pericardial collar and Teflon-buttressed sutures at the ventriculo-aortic junction with no aneurysm/pseudoaneurysm formation.

the iEOA was $\leq 0.65 \mathrm{~cm}^{2} / \mathrm{m}^{2}$. All late echoes have been grouped into one time period (48 months) and a range no greater than 6 months.

\section{Computed Tomographic Angiocardiography}

All scans $(n=109)$ were performed on a third-generation, $384(2 \times 192)$-slice, dual-source computed tomography scanner (SOMATOM FORCE; Siemens, Munich, Germany). Slices were reconstructed of $0.6-\mathrm{mm}$ section thickness and increment of $0.4 \mathrm{~mm}$, using a medium sharp kernel (Bv40), with a model based iterative reconstruction strength level 3 (ADMIRE; Siemens Healthcare). Multiplanar reformatted images and volume rendered images were reconstructed and analyzed (Video 1).

\section{Surgical Techniques}

Intraoperative transesophageal echocardiography was performed using a Philips X7-2T probe on all patients both before and after surgery. The technical details of the surgical steps have been enumerated in Video 1.

The St Jude (SJM Regent; St. Jude Medical Inc, St Paul, Minn) mechanical prostheses (SJM $19 \mathrm{~mm}, 34$ patients; $21 \mathrm{~mm}, 60$ patients; $23 \mathrm{~mm}, 21$ patients) (Table 1) was used in all patients.

The extension of the aortotomy was decided on operation table depending on the degree of annular enlargement required for a particular patient. A simple extension of the oblique horseshoe-shaped aortotomy until the level of the aortic annulus allows 2- to 5-mm annulus enlargement and the subannular extension allows 5- to 10-mm ARE.

In patients undergoing the classical Nicks' procedure $(n=78)$, the oblique horseshoe-shaped aortotomy was continued across the mid-portion of the noncoronary sinus into the fibrous subaortic curtain. After excising the aortic valve, the subannular aortic defect was reconstructed using an autologous, unfixed pericardium. A pledgeted 4-0 polypropylene suture started at the apex of the aortotomy and extended in a running fashion on both sides of the annular defect. Typically, the suture was continued approximately $2 \mathrm{~cm}$ beyond the aortic annulus. To avoid subannular bleeding, a second layer of 5-0 polypropylene was placed over the first suture line. The valve sizer was placed in the subaortic annulus to confirm proper sizing and position of the valve in the subcoronary location (Video 1).
The neocommissure was then estimated based on the position of the patch and marked. Similar to an AVR in a routine annulus, we used interrupted pledgeted 2-0 braided Ticron-polyester coated (M/s Covidien, Santo Domingo, Dominican Republic) suture. At the transition zone and augmented segment, the pledgeted sutures were placed from outside the patch into the aorta, leaving the pledgets externally without causing crimping effect. The sutures were passed through the sewing cuff of the mechanical aortic prosthesis and the valve was seated in the intra-annular position, ensuring no encroachment of the coronary ostia. We implanted the majority of valves in the intra-annular position; however, we occasionally place mechanical valves in the supra-annular position. Disc movement was checked for interference by the subvalvular muscle.

The aortotomy opposite the patch was closed directly using 4-0 polypropylene suture. The patch was trimmed to the size of the remaining defect, and the original 4-0 polypropylene suture was continued around the patch to complete closure of the aortotomy.

A subset of patients underwent a modified Nicks' procedure $(\mathrm{n}=37)$, in whom the aortotomy incision was continued into the mid-portion of the noncoronary sinus across the aortic annulus and the fibrous subaortic curtain, which allowed implantation of one-size larger aortic prosthesis. In these cases, the incision below the subaortic annulus was limited to less than $1 \mathrm{~cm}$ and the anterior mitral leaflet was not incised as much as in the original Nicks.

After enlarging the aortic root, we implanted an appropriate-sized larger aortic prosthesis using pledgeted, interrupted polyester sutures, placing the pledgets from outside the aorta to the sewing ring of the prosthesis in the area of the noncoronary sinus. After checking the disc movement, we passed four 4-0 pledgeted polypropylene mattress sutures from the sewing ring of the prosthesis to the pericardial patch, ensuring they retained a $0.5-\mathrm{cm}$ pericardial cuff. After sitting the pericardial patch, we repaired the newly constructed annulus over the noncoronary sinus using a second continuous layer of 4-0 polypropylene suture and the retained pericardial cuff, thus ensuring adequate hemostasis.

\section{Statistical Analysis}

Statistical analysis was performed using STATA 14.0 Software (StataCorp, College Station, Tex). Qualitative data were expressed as mean \pm standard deviation (SD), if normality exists; otherwise, median 
TABLE 1. Demographic details of patients undergoing aortic root enlargement with isolated aortic valve replacement and combined aortic and mitral valve replacement in the study group $(n=115)$

\begin{tabular}{lc}
\hline \multicolumn{1}{c}{ Variables } & Number $(\%)$ \\
\hline Male & $71(61.7)$ \\
Age, y & \\
$\quad \begin{array}{l}\text { Aortic valve replacement, median age, y (IQR) } \\
\text { Aortic and mitral valve replacements, median } \\
\quad \text { age, y (IQR) }\end{array}$ & $27.5(21-47)$ \\
\end{tabular}

Age distribution, $\mathrm{y}$

$\begin{array}{ll}11-20 & 40(34.8) \\ 21-40 & 23(20) \\ 41-60 & 25(21.7) \\ 61-72 & 27(23.4)\end{array}$

$\begin{array}{lc}\text { Dyspnea on exertion } & 115(100) \\ \text { Congestive cardiac failure } & 22(19.1) \\ \text { Preoperative New York Heart Association class } & \\ \quad \text { II } & 3(2.6) \\ \text { III } & 82(71.3) \\ \text { IV } & 30(26.1) \\ \text { Preoperative thromboembolism } & 5(4.3) \\ \text { Presence of preoperative left atrium/left atrial } & 14(12.2) \\ \quad \text { appendage clot } & \end{array}$

Previous balloon mitral valvotomy 5 (4.3)

\begin{tabular}{|c|c|}
\hline Systemic hypertension & $35(30.4)$ \\
\hline Atrial fibrillation & $94(81.7)$ \\
\hline \multicolumn{2}{|l|}{ Pathology } \\
\hline Predominant aortic stenosis & $52(45.2)$ \\
\hline $\begin{array}{l}\text { Mixed lesion: aortic stenosis and aortic } \\
\text { regurgitation }\end{array}$ & $15(13)$ \\
\hline Combined aortic and mitral stenosis & $29(25.2)$ \\
\hline $\begin{array}{l}\text { Mixed lesion: aortic stenosis, mitral stenosis } \\
\text { and mitral regurgitation }\end{array}$ & $19(16.5)$ \\
\hline $\begin{array}{l}\text { Coexisting tricuspid stenosis and tricuspid } \\
\text { regurgitation }\end{array}$ & $11(9.6)$ \\
\hline $\begin{array}{l}\text { Preoperative left ventricular ejection fraction, } \\
\text { mean } \pm \text { SD }\end{array}$ & $52.5 \pm 6.4$ \\
\hline Left ventricular ejection fraction $<0.30$ & $19(16.5)$ \\
\hline \multicolumn{2}{|l|}{ Type of operation } \\
\hline $\begin{array}{l}\text { Aortic valve replacement with aortic root } \\
\text { enlargement (Nicks) }\end{array}$ & $67(58.2)$ \\
\hline $\begin{array}{l}\text { Aortic and mitral valve replacement }+ \text { aortic } \\
\text { root enlargement (Nicks) }\end{array}$ & $48(41.7)$ \\
\hline Concomitant tricuspid valve repair & $11(9.5)$ \\
\hline $\begin{array}{l}\text { Concomitant Dacron patch closure of atrial } \\
\text { septal defect }\end{array}$ & $2(1.7)$ \\
\hline Concomitant coronary artery bypass grafting & $2(1.7)$ \\
\hline \multicolumn{2}{|l|}{$\begin{array}{l}\text { Size of the implanted aortic mechanical } \\
\text { prosthesis (St Jude Medical Reagent) }\end{array}$} \\
\hline $19 \mathrm{~mm}$ & $34(29.6)$ \\
\hline $21 \mathrm{~mm}$ & $60(52.2)$ \\
\hline $23 \mathrm{~mm}$ & $21(18.2)$ \\
\hline
\end{tabular}

TABLE 1. Continued

\begin{tabular}{|c|c|c|c|c|}
\hline \multicolumn{3}{|c|}{ Variables } & \multicolumn{2}{|r|}{ Number $(\%)$} \\
\hline \multicolumn{5}{|c|}{ Implanted size of the aortic prosthesis } \\
\hline \multicolumn{3}{|l|}{1 size larger } & \multicolumn{2}{|r|}{$65(56.5)$} \\
\hline \multicolumn{3}{|l|}{2 sizes larger } & \multicolumn{2}{|r|}{$50(43.5)$} \\
\hline \multicolumn{5}{|c|}{ Aortic crossclamp time, min } \\
\hline \multicolumn{3}{|c|}{$\begin{array}{l}\text { Aortic valve replacement with Nicks' } \\
\text { procedure, mean } \pm \mathrm{SD} \text { (range) }\end{array}$} & \multicolumn{2}{|c|}{$54 \pm 19.6(39-106)$} \\
\hline \multicolumn{3}{|c|}{$\begin{array}{l}\text { Aortic and mitral valve replacements with } \\
\text { Nicks, mean } \pm \text { SD (range) }\end{array}$} & \multicolumn{2}{|c|}{$98.3 \pm 30.2(73-119)$} \\
\hline \multicolumn{5}{|c|}{ Cardiopulmonary bypass time, min } \\
\hline \multicolumn{3}{|c|}{$\begin{array}{l}\text { Aortic valve replacement with Nicks' } \\
\text { procedure, mean } \pm \mathrm{SD} \text { (range) }\end{array}$} & \multicolumn{2}{|c|}{$116.6 \pm 27.3(97-194)$} \\
\hline \multicolumn{3}{|c|}{$\begin{array}{l}\text { Aortic and mitral valve replacements with } \\
\text { Nicks, mean } \pm \text { SD (range) }\end{array}$} & \multicolumn{2}{|c|}{$133.4 \pm 30.2(73-217)$} \\
\hline \multicolumn{5}{|c|}{ Size of the implanted mechanical prosthesis (St Jude Medical) } \\
\hline & $19 \mathrm{~mm}$ & \multicolumn{2}{|c|}{$21 \mathrm{~mm}$} & $23 \mathrm{~mm}$ \\
\hline $\begin{array}{l}\text { Peak aortic } \\
\text { transprosthetic } \\
\text { gradient }\end{array}$ & $\begin{array}{l}18.0 \pm 4.0 \\
\mathrm{~mm} \mathrm{Hg}\end{array}$ & \multicolumn{2}{|c|}{$\begin{array}{l}18.0 \pm 2.9 \\
\mathrm{~mm} \mathrm{Hg}\end{array}$} & $\begin{array}{l}18.0 \pm 2.0 \\
\mathrm{~mm} \mathrm{Hg}\end{array}$ \\
\hline $\begin{array}{l}\text { Mean aortic } \\
\text { transprosthetic } \\
\text { gradient }\end{array}$ & $\begin{array}{l}12.0 \pm 4.0 \\
\mathrm{~mm} \mathrm{Hg}\end{array}$ & \multicolumn{2}{|c|}{$\begin{array}{l}12.0 \pm 4.1 \\
\mathrm{~mm} \mathrm{Hg}\end{array}$} & $\begin{array}{l}12.0 \pm 4.0 \\
\mathrm{~mm} \mathrm{Hg}\end{array}$ \\
\hline $\begin{array}{l}\text { Indexed } \\
\text { aortic effective } \\
\text { orifice area }\end{array}$ & $\begin{array}{l}0.80 \pm 0.18 \\
\mathrm{~cm}^{2} / \mathrm{m}^{2}\end{array}$ & \multicolumn{2}{|c|}{$\begin{array}{l}0.96 \pm 0.72 \\
\mathrm{~cm}^{2} / \mathrm{m}^{2}\end{array}$} & $\begin{array}{l}1.14 \pm 0.36 \\
\mathrm{~cm}^{2} / \mathrm{m}^{2}\end{array}$ \\
\hline
\end{tabular}

$I Q R$, Interquartile range; $S D$, standard deviation.

with interquartile range were reported. Normality was established using histogram plots and the Kolmogorov-Smirnov test. Qualitative data were expressed as numbers and percentages. Echocardiographic parameters over a period of time during follow-up were also tested for normality. Examination revealed aortic valve annular diameter and iEOA $\left(\mathrm{cm}^{2} / \mathrm{m}^{2}\right)$ were following the normality assumption. Other echocardiographic parameters, namely, LVEF, thickness of the interventricular septum, peak and mean transaortic valvar/prosthetic gradient, and aortic root diameter at sinus of Valsalva and sinotubular junction followed non-normality.

A paired $t$ test was used to compare the aortic valve annular diameter and iEOA area between the preoperative values and values at the time of discharge/late follow-up, whereas the signed-rank test was used to compare other echocardiographic variables (LVEF, thickness of the interventricular septum, peak and mean transaortic valvar/prosthetic gradient, aortic root diameter at sinus of Valsalva and sinotubular junction) between the preoperative value and values at the time of discharge and late follow-up. The survival probability with $95 \%$ confidence intervals was reported at various time intervals with the Kaplan-Meier technique.

\section{RESULTS}

\section{Study Population}

ARE was performed on 115 patients aged between 11 and 72 years (AVR: median age 30 years [interquartile range, 21-47 years]; aortic and mitral valve replacement: median age 27.5 years [interquartile range, 20-37.5 years]), and body surface area between 0.91 and $1.85 \mathrm{~m}^{2}$ (mean $\pm \mathrm{SD}=1.34 \pm 0.22 \mathrm{~m}^{2}$ ). The study population of 115 patients included $67(58.2 \%)$ patients of AVR and 


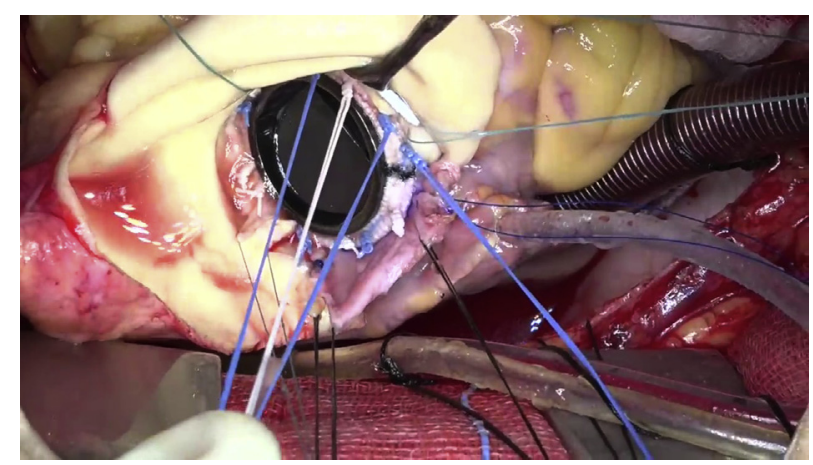

VIDEO 1. Surgical techniques of aortic root enlargement (Nicks' procedure) and aortic valve replacement are discussed in a patient undergoing aortic root enlargement for aortic stenosis and small aortic annulus. A video presentation of the surgical techniques of aortic root enlargement (Nicks' procedure) and aortic valve replacement in a patient undergoing aortic root enlargement for aortic stenosis and small aortic annulus.

- Following median sternotomy, the thymus was subtotally excised, with care taken not to expose the brachiocephalic vein. The pericardium was incised to the right of midline and left in situ in between 4-0 silk stay sutures.

- Moderately hypothermic $\left(28-32^{\circ} \mathrm{C}\right)$ cardiopulmonary bypass was established using ascending aortic and bicaval cannulation.

- The left heart was vented through the right superior pulmonary vein using a no. 14 sump suction vent. The left ventricular vent was inserted before aortic crossclamp on a partially filled heart with the ventilation stopped to prevent intracardiac air suction.

- After crossclamping the aorta, we opened the aorta $2 \mathrm{~cm}$ above the right coronary sinus through an oblique horse-shoe shaped incision that was carried down on the right toward the mid-portion of the noncoronary sinus. Myocardial protection was achieved using selective ostial cold St Thomas II (4:1)-based blood cardioplegia and topical cooling using ice-cold saline.

- After placing 3 commissural stay sutures, we excised the diseased, stenosed, calcified aortic valve. Since the aortic annulus was admitting insertion of only a 19-mm St Jude valve sizer, small for the patient, the incision was made to enlarge the aortic annulus.

- The aortotomy was extended further into the noncoronary sinus, across the aortic annulus, and into the anterior leaflet of the mitral valve. Care was taken to limit the incision into the anterior mitral leaflet by about $1 \mathrm{~cm}$ and not to enter the roof of the left atrium, which was gently swept away from the incision site. - A generous piece of previously prepared autologous pericardium (about $3 \times 6 \mathrm{~cm}$ ) was cut. It is desirable to cut a size larger and trim the excess, rather than end up with too small a piece.

- The pericardium was positioned on the retractor with stay sutures in the corners and the smooth inner surface faced down opposite the surgeon, toward the luminal side.

- A 4-0 polypropylene suture was used to suture the pericardium, starting at the base of the root enlargement incision. Four bites were taken and the pericardium was snuggly pulled down.

- Each arm of 4-0 polypropylene suture was followed up on either side of the respective cut edge of the annulus and the aortic valve to a level approximately $2 \mathrm{~cm}$ above the original annulus. As a precaution, a second suture layer of 5-0 polypropylene was placed over the first suture line starting at one end of the patch to the other end. Each end of the second suture was tied to the end of the 4-0 suture line. The additional second suture eliminates the risk of bleeding from the patch suture line below the sewing ring. Such bleeding below the sewing ring from the subannular area can be catastrophic after completion of the procedure.
ARE and $48(41.7 \%)$ patients with aortic and mitral valve replacement and ARE (Table 1).

The etiology appeared rheumatic in $62(53.9 \%)$ patients, degenerative, calcific on a bicuspid or tricuspid aortic valve ( $\mathrm{n}=52 ; 45.2 \%)$, and hereditary homozygous hypercholesterolemia in $1(0.9 \%)$ patient. ${ }^{18}$ Overall, $17.4 \%$ (20 of 115$)$ patients had both aortic and mitral valvar calcification with variable annular extension. The mitral valve in this study group was extensively scarred with severe sub-sinotubular fusion and foreshortening of the chordal apparatus and was deemed irreparable.

Mean ischemic time for AVR + ARE was $54 \pm 19.6$ minutes (range, 39-106); and for AVR,

\section{A} aortic annulus. The position of the valve was assessed, the coronary ostia were identified, and the neocommissure on the pericardial patch over the noncoronary sinus area was marked using a marking pencil.

- The aortic valve was replaced using a number 21-mm St Jude Regent Mechanical Heart Valve (St Jude Medical Inc, St Paul, Minn). We used interrupted, pledgeted 2-0 braided, coated Ticron polyester sutures (M/s Covidien, Santo Domingo, Dominican Republic). At the transition zone and augmented segment, the pledgeted sutures were placed from outside the patch into the aorta leaving the pledgets externally without causing crimping effect. The same sutures were passed through the sewing cuff of the mechanical aortic prosthesis and the valve was seated in the intra annular position ensuring no encroachment of the coronary ostia. We implanted the valve in the intra annular position. Disc movement was checked for interference by the subvalvular muscle. The aortotomy opposite the patch was closed directly using 4-0 polypropylene suture. The patch was trimmed to the size of the remaining defect, and the original 4-0 polypropylene suture was continued around the patch to complete closure of the aortotomy.

- The aortic crossclamp was released, thus restoring myocardial perfusion and weaned off cardiopulmonary bypass with stable hemodynamics. Techniques of Computed Tomographic Angiography (Electronics)

All scans were performed on a third-generation, $384(2 \times 192)$-slice, dual-source computed tomography scanner (SOMATOM FORCE; Siemens, Munich, Germany). It has a rotation time of up to 0.25 seconds with a temporal resolution of up to 66 milliseconds and spatial resolution of $0.24 \mathrm{~mm}$. No form of heart rate control was required. Retrospective electrocardiogramgated computed tomography angiography examination was performed after injection of non-ionic iodinated contrast $(1.0 \mathrm{~mL} / \mathrm{kg}$ body weight $)$ was administered via peripheral intravenous line at flow rate of $4.0 \mathrm{~mL} / \mathrm{s}$ followed by a saline chaser $(50 \mathrm{~mL})$ injected at the same flow rate. A "bolus-tracking" method was used whereby computed tomography acquisition was automatically triggered when contrast opacification threshold of 100 Hounsfield units was achieved in the ascending aorta on the monitoring sequence. Automated tube voltage selection and automated tube current modulation based on body habitus (CARE kV and CARE Dose4D; Siemens Healthcare) were enabled. Slices were reconstructed of $0.6-\mathrm{mm}$ section thickness and increments of $0.4 \mathrm{~mm}$, using a medium sharp kernel (Bv40), with a model based iterative reconstruction strength level 3 (ADMIRE; Siemens Healthcare). Multiplanar reformatted images and volume rendered images were reconstructed and analyzed. Video available at: https://www.jtcvs.org/article/S2666-2507(20)30392-8/fulltext. 
TABLE 2. Early and late postoperative outcomes of the patients undergoing aortic root enlargement with aortic valve replacement or aortic and mitral valve replacement in this study

\begin{tabular}{|c|c|}
\hline Variables & Number $(\%)$ \\
\hline \multicolumn{2}{|l|}{ Mortality } \\
\hline Early (within $30 \mathrm{~d}$ ) & 2 (1.7): Congestive heart failure $(\mathrm{n}=1)$, intractable ventricular fibrillation $(\mathrm{n}=1)$ \\
\hline Late & $\begin{array}{l}4(3.5) \text { : Ventricular fibrillation }(n=1) \text {, intracranial bleeding }(n=2), \\
\text { cerebral thromboembolism }(n=1) \text { at } 60,72,80 \text {, and } 98 \text { mo after operation }\end{array}$ \\
\hline Intensive care unit stay $(>48 \mathrm{~h})$ & $8(6.9)$ \\
\hline Prolonged mechanical ventilation ( $>96 \mathrm{~h})$ & $7(6.1)$ \\
\hline \multicolumn{2}{|l|}{ Major postoperative complications } \\
\hline Transient atrial fibrillation & $8(6.9)$ \\
\hline Renal insufficiency requiring peritoneal dialysis & $1(0.8)$ \\
\hline Complete heart block requiring permanent pace maker & $1(0.8)$ \\
\hline Postoperative drainage (mean $12 \mathrm{~h}$ ) & $200 \pm 70 \mathrm{~mL}$ \\
\hline Re-exploration for bleeding & $2(1.7)$ \\
\hline Mitral prosthetic thrombosis & $\begin{array}{l}4 \text { (4.4): successful thrombosis }(n=3) \text {, major cerebrovascular accident } \\
\text { following thrombolysis }(n=1)\end{array}$ \\
\hline Cerebral thromboembolism & $\begin{array}{l}5(4.3) \text { : death }(\mathrm{n}=1), \text { recovered with residual weakness }(\mathrm{n}=2) \\
\text { complete recovery }(\mathrm{n}=2)\end{array}$ \\
\hline Mean $12 \mathrm{~h}$ postoperative drainage & $200 \pm 70 \mathrm{~mL}$ \\
\hline \multicolumn{2}{|l|}{ Perioperative arrhythmias } \\
\hline Supraventricular & $28(24.3)$ \\
\hline Ventricular & $7(6.1)$ \\
\hline Premature ventricular complexes & $6(5.2)$ \\
\hline Complete heart block requiring permanent pacemaker & $1(0.8)$ \\
\hline
\end{tabular}

MVR + ARE was 98.3 \pm 30.2 minutes (range, 73-119). Mean cardiopulmonary bypass time for AVR + ARE was $116.6 \pm 27.3$ minutes (range, 97-194), and for AVR, MVR + ARE was $133.4 \pm 30.2$ minutes (range, 73-217).

\section{Operative Mortality and Morbidity}

There were $2(1.7 \%)$ operative deaths due to intractable congestive cardiac failure 15 days after combined AVR and MVR ( $\mathrm{n}=1)$, and intractable ventricular fibrillation $(\mathrm{n}=1)$. Intensive care unit stay $>48$ hours was required in $8(6.9 \%)$ patients, and prolonged mechanical ventilation (>96 hours) was required in $7(6.1 \%)$ patients. Major postoperative complications included transient atrial fibrillation in $8(6.9 \%)$ patients, renal insufficiency requiring peritoneal dialysis in $1(0.8 \%)$ patient, and complete atrioventricular block in $1(0.8 \%)$ patient. The mean 12-hour postoperative drainage was $200 \pm 70 \mathrm{~mL}$ (Table 2).

Chest re-exploration for bleeding in the immediate postoperative period was required in $2(1.7 \%)$ patients and the cause of the bleeding was from the pericardiophrenic vessel and an injured thymic vein respectively. There was no bleeding from the aortotomy/root enlargement site, and no patient required fibrillin glue as a topical hemostatic agent. Patients were discharged 7 to 18 days after surgery (mean, $8.6 \pm 4$ days) (Table 2).

\section{Late Outcomes}

There were $4(3.5 \%)$ late deaths, 60, 72, 80, and 98 months after surgery due to ventricular fibrillation $(\mathrm{n}=1)$, intracranial bleeding $(\mathrm{n}=2)$, and cerebral thromboembolism $(\mathrm{n}=1)$, respectively. Four $(4.4 \%)$ patients had prosthetic mitral valve thrombosis. One of them developed major cerebrovascular accident after streptokinase administration and subsequently died. Three patients had successful thrombolysis. Five patients had thromboembolic complications. One of them died, 2 recovered with residual weakness, and 2 recovered completely. No single factor was found to be associated with incidence of thromboembolism. No patient suffered from prosthetic valve endocarditis (Table 2).

\section{Perioperative Myocardial Infarction and Arrhythmias}

No patient sustained perioperative myocardial infarction. Rhythm abnormalities included supraventricular arrhythmias $(n=28,24.3 \%)$, ventricular arrhythmia $(n=7$; $6.1 \%)$, premature ventricular contraction $(\mathrm{n}=6 ; 5.2 \%)$, and complete heart block requiring implantation of permanent pacemaker in $1(0.8 \%)$ patient (Table 2).

\section{Follow-up}

Follow-up was $100 \%$ complete (range, 1-276 months) and yielded 1117.25 patient-years of data with a mean follow-up time of 123.11 months $( \pm$ SD 77.67; median, 138 months). One hundred nine (94.8\%) patients achieved the mandatory 24-month postoperative follow-up. The survival probability from Kaplan-Meier at 276 months was 


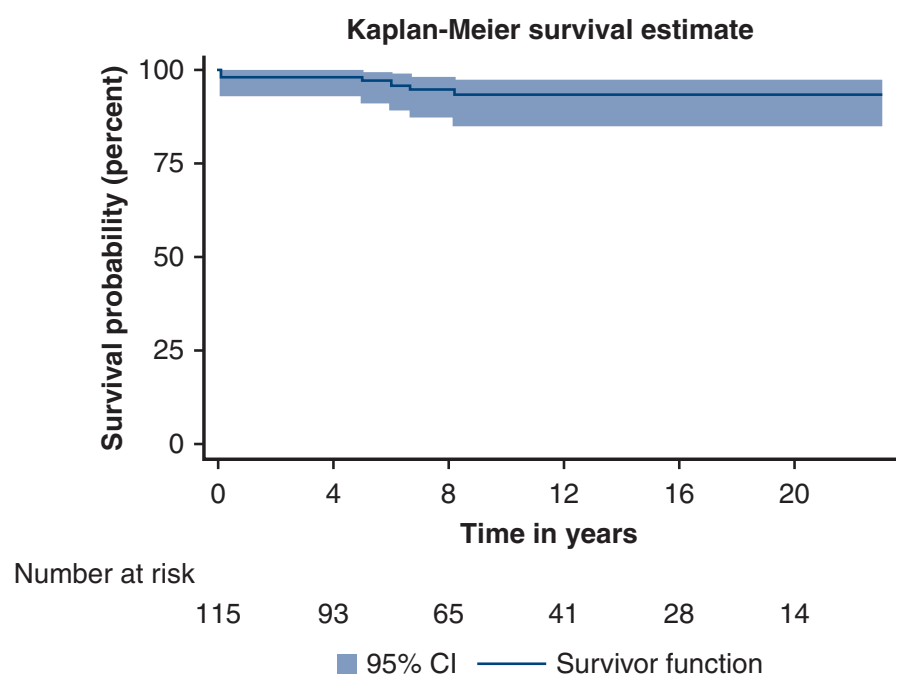

FIGURE 2. Survival probability from Kaplan-Meier curve of patients $(\mathrm{n}=115)$ undergoing Nicks' posterior aortic root enlargement and isolated aortic valve replacement and combined aortic and mitral valve replacement. $C I$, Confidence interval.

$93.3 \% \pm 0.03 \%(95 \%$ confidence interval, $0.85-0.96)$ (Figure 2). One hundred one $(92.6 \%)$ survivors were in New York Heart Association functional class I or II at their last follow-up.

\section{Data Analyses and Study Interpretation of the Echocardiographic Data}

To assess the characterization of echocardiographic variables in survivors of ARE $(n=109)$, paired analysis reveals the following results (Table 3):

1. There was a statistically significant increase in LVEF in the immediate $(P<.0001)$ as well as late postoperative period $(P<.0001)$. The LVEF improved from a preoperative mean value of $55.2 \pm 7.4$ to $58.5 \pm 6.0$ (at discharge) to $62.2 \pm 4.4$ (at late follow-up).

2. There was significant reduction of thickness of interventricular septum at discharge (mean $\pm \mathrm{SD}$, $-2.4 \pm 1.1 \mathrm{~mm}, P<.0001)$, as well as in late follow-up (mean $\pm \mathrm{SD},-1.1 \pm 0.4 \mathrm{~mm}, P<.0001$ ).

3. The iEOA improved significantly in all patients following ARE and AVR or AVR with MVR. After surgery, the mean iEOA was $1.07 \pm 0.1 \mathrm{~cm}^{2} / \mathrm{m}^{2}$, $P<.0001$, and at late follow-up, it remained the same.

4. There was statistically significant reduction in peak and mean transaortic prosthetic gradient in the immediate postoperative $(P<.0001)$ as well as in late follow-up period $(P<.0001)$. The mean transaortic gradient reduced from $59.9 \pm 7.6$ (preoperative) to $15.3 \pm 1.7$ (at discharge) to $14.6 \pm 1.7$ (late follow-up).

5. There was significant improvement of aortic root dimensions at all 3 levels (aortic annulus, sinus of Valsalva, and sinotubular junction) in the immediate postoperative period $(P<.0001)$, as well as at late follow-up $(P<.0001)$ (Table 3$)$.

\section{Evaluation of PPM}

Intraoperatively, the aortic annulus size ranged from 15 to $20 \mathrm{~mm}$ (mean, $18.2 \pm 1.2$ ). The mean size of the implant prostheses was $21.2 \pm 1.6 \mathrm{~mm}$. A prosthesis 1 size larger was implanted in 65 patients, and 2 sizes larger was implanted in 50 patients; mild PPM was observed in 3 patients with a $19 \mathrm{~mm}$ bioprosthesis. In all other patients, the iEOA was $\geq 0.85 \mathrm{~cm}^{2} / \mathrm{m}^{2}$ (mean iEOA, $0.90 \pm 0.04 \mathrm{~cm}^{2} / \mathrm{m}^{2}$ ) at follow-up. Had the prosthetic valve been implanted on the basis of intraoperative measurements, there would have been moderate PPM in all patients (Table 1).

\section{Angiographic Assessment of the Aortic Root}

At a mean follow-up of $123.11 \pm 77.67$ months, 109 patients underwent computed tomographic angiocardiography in the late postoperative period. None of the survivors ( $\mathrm{n}=109)$ demonstrated any periprosthetic leakage, aneurysm or pseudoaneurysm formation of the aortic root, and calcification of the pericardial patch (Figure 3, A-P). Five $(4.7 \%)$ patients had mild speckle of ascending aortic wall calcification. The coronary ostia were normal.

\section{DISCUSSION}

Small aortic annulus presents the challenge of avoiding PPM with least perioperative mortality and morbidity. Pibarot and colleagues ${ }^{4}$ have shown that in the small prosthetic sizes, an increase of one valve size chronically reduce cardiac work by approximately $20 \%$. As a result, there is improved LV mass regression, postoperative 
TABLE 3. Assessment of 2-dimensional echocardiographic-derived parameters over a period of time before and after aortic root enlargement of all long-term survivors $(n=109)$ in this study

\begin{tabular}{|c|c|c|c|c|c|}
\hline Variables & $\begin{array}{c}\text { Preoperative } \\
(\mathbf{n}=109)\end{array}$ & $\begin{array}{l}\text { At discharge } \\
(\mathbf{n}=109)\end{array}$ & $\begin{array}{c}\text { At late } \\
\text { follow-up } \\
(n=109)\end{array}$ & $\begin{array}{l}\text { Preoperative } \\
\text { vs discharge } \\
(\mathbf{n}=109)\end{array}$ & $\begin{array}{l}\text { Preoperative } \\
\text { vs late } \\
\text { follow-up } \\
(\mathbf{n}=109)\end{array}$ \\
\hline $\begin{array}{l}\text { Left ventricular ejection fraction }(\%), \\
\text { median (minimum-maximum) }\end{array}$ & $55(37-68)$ & $58(46-68)$ & $62(49-72)$ & $P<.0001$ & $P<.0001$ \\
\hline $\begin{array}{l}\text { Thickness of the interventricular septum, mm, } \\
\text { median (minimum-maximum) }\end{array}$ & $14(11-17)$ & $12(10-15)$ & $11(9-19)$ & $P<.0001$ & $P<.0001$ \\
\hline $\begin{array}{l}\text { Indexed aortic effective orifice area, } \\
\mathrm{cm}^{2} / \mathrm{m}^{2} \text {, mean } \pm \mathrm{SD} \text { (range) }\end{array}$ & $0.83 \pm 0.1(0.6-1.1)$ & $1.07 \pm 0.1(0.9-1.2)$ & $1.07 \pm 0.1(0.9-1.2)$ & $P<.0001$ & $P<.0001$ \\
\hline $\begin{array}{l}\text { Peak transaortic valvar/prosthetic gradient, } \\
\text { mm Hg, median (minimum-maximum) }\end{array}$ & $86(11-144)$ & $17(14-21)$ & $15(12-20)$ & $P<.0001$ & $P<.0001$ \\
\hline $\begin{array}{l}\text { Mean aortic transprosthetic gradient, } \\
\mathrm{mm} \mathrm{Hg} \text {, median (minimum-maximum) }\end{array}$ & $59(46-80)$ & $15(11-20)$ & $15(11-19)$ & $P<.0001$ & $P<.0001$ \\
\hline $\begin{array}{l}\text { Aortic valve annular diameter, } \mathrm{mm} \text {, } \\
\text { mean } \pm \mathrm{SD} \text { (range) }\end{array}$ & $16.6 \pm 1.4(14-19)$ & $20.7 \pm 1.4(19-23)$ & $20.7 \pm 1.4(19-23)$ & $P<.0001$ & $P<.0001$ \\
\hline $\begin{array}{l}\text { Aortic root diameter at sinus of Valsalva, mm, } \\
\text { median (minimum-maximum) }\end{array}$ & $29(25-32)$ & $32(29-35)$ & $33(30-36)$ & $P<.0001$ & $P<.0001$ \\
\hline $\begin{array}{l}\text { Aortic root diameter at sinotubular junction, mm, } \\
\text { median } \\
\text { (minimum-maximum) }\end{array}$ & $30(28-33)$ & $33(30-36)$ & $33(31-37)$ & $P<.0001$ & $P<.0001$ \\
\hline
\end{tabular}

functional class/exercise tolerance, and both early and late survival. ${ }^{1,7,19-23}$

Definitions of PPM in the published literature range from an indexed orifice area of $\leq 0.6 \mathrm{~cm}^{2} / \mathrm{m}^{2}$ to $\leq 0.85 \mathrm{~cm}^{2} / \mathrm{m}^{2}$ as well as dispute over the more appropriate measure of orifice area (geometric or effective). ${ }^{15,24,25}$ Pibarot and colleagues ${ }^{4}$ have demonstrated that indexed geometric orifice area grossly overestimates PPM and correlates poorly with the iEOA and therefore should not be used to identify patients with high transvalvular gradients as the basis of PPM. Some investigators have demonstrated no association between apparent mismatch and postoperative mortality. ${ }^{22,24-26}$ It is imperative to note that the definition of mismatch in these studies were based on the indexed internal geometric orifice area of the prosthetic valve. ${ }^{22,24-26}$ Kratz and associates ${ }^{27}$ recommended that in patients with a body surface area $>1.9 \mathrm{~m}^{2}$ with a $19-\mathrm{mm}$ or 21-mm annulus, a St Jude valve should be used or an ARE procedure should be performed. In a study of the Carpentier-Edwards Perimount prosthesis, Tasca and associates $^{22}$ in 2003 did not find any significant difference between 19-mm, 21-mm, and 23-mm Carpentier-Edwards Perimount prosthesis valve sizes on postoperative LV mass regression. Available evidence, however, suggests that it is the relationship of the hydrodynamic properties of a given valve type and iEOA that accurately predicts mismatch.
Many surgeons are reluctant to perform ARE out of concern that this adjunctive procedure will increase the operative morbidity and mortality. ${ }^{27,28}$ Other concerns have been subannular bleeding, impedance to outflow imposed by angular distortion of the LVOT with overriding of the prosthesis on the anterior mitral leaflet, restricted leaflet motion, especially with the St Jude Medical Regent model secondary to subvalvular muscular shelf of LVOT, excessive bypass and ischemic times, paraprosthetic

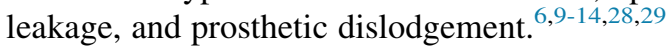

Several strategies are available in the surgeon's armamentarium when confronted with the small aortic root. The available options are (1) posterior ARE techniques (Nicks' and Manouguian's procedures); (2) KonnoRastan procedure; (3) Ross procedure; and (4) stentless aortic valves and sutureless prosthesis. ${ }^{26}$ The KonnoRastan procedure offers the greatest degree of ARE; however, it is technically more complicated and requires the creation of right ventriculotomy and ventricular septal defect with double-patch closure of both. The surgical risk of this procedure includes injury to the septal perforators, conduction system, and places the patient at risk of intracameral fistulae. ${ }^{4-29}$

Stenseth and colleagues ${ }^{30}$ introduced the pericardial patch enlargement of aortic outflow tract, to prevent tertiary orifice obstruction after implantation of the Starr Edwards prosthesis. It has been the authors' practice to perform 

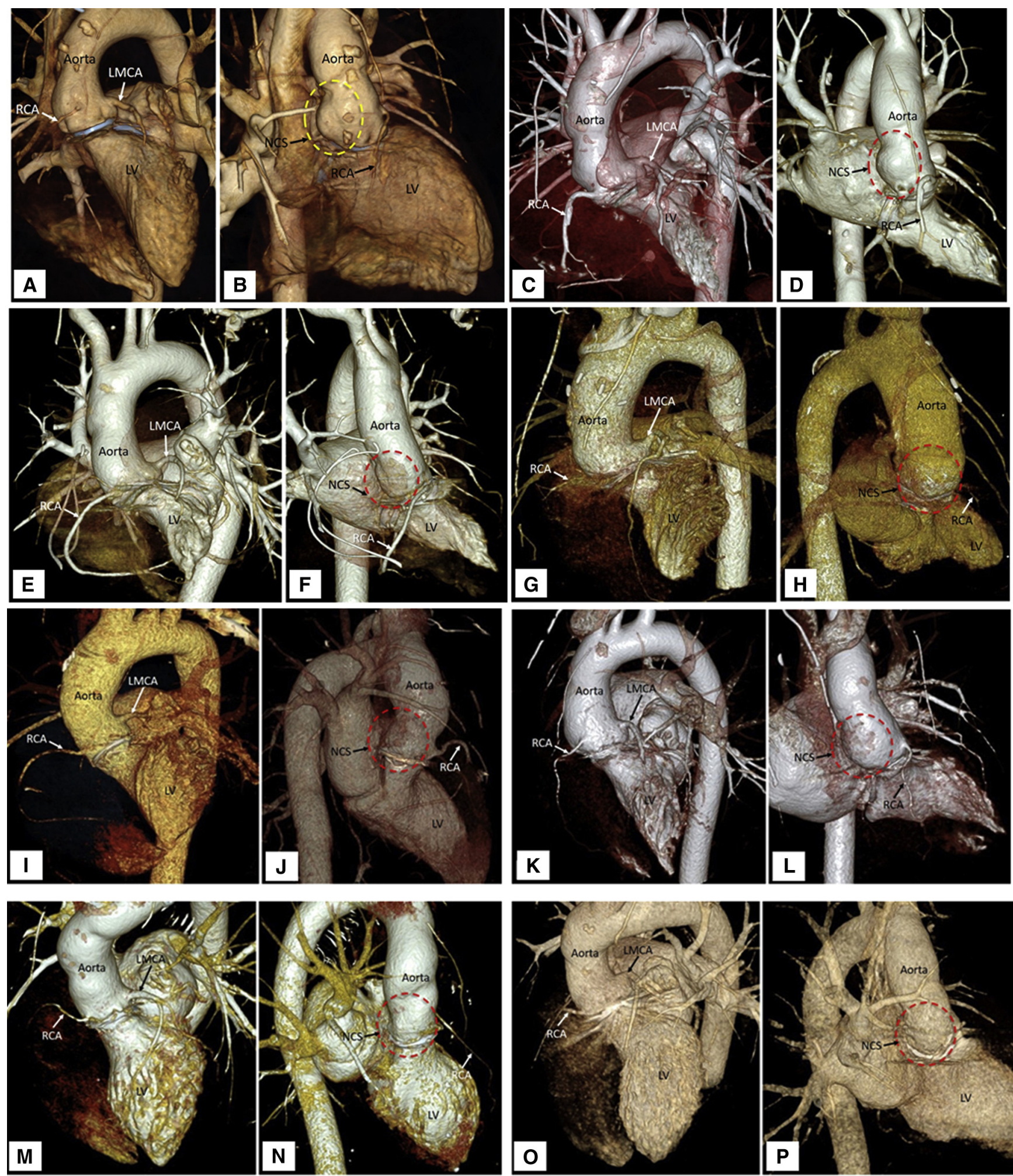

FIGURE 3. A-P, Postoperative computerized volume-rendered images of computed tomographic angiography in the left anterior oblique and right anterior oblique projections with cranial tilt on 8 patients in the study group showing nondilated aortic root with no aneurysm or pseudoaneurysm formation at the enlarged ventriculo-aortic junction on long-term follow-up. There is no coronary arterial kinking or narrowing. $R C A$, Right coronary artery; $L M C A$, left main coronary artery; $L V$, left ventricle; $N C S$, non-coronary sinus. 
Nicks' posterior ARE for management of the small aortic annulus whenever possible. We find the more complex alternatives promulgated today using homografts, stentless xenografts, autografts as mini root, or full root replacements unappealing, as these procedures are associated with an almost 3-fold greater operative risk than simple AVR, in the Society of Thoracic Surgeons database. ${ }^{18}$

The normalization of LV mass following surgery is a complex phenomenon. Along with PPM, reversible and irreversible changes in the hypertrophied myocytes and interstitium, angiotensin-converting enzyme gene, and insulin growth factor-I have been variously incriminated as factors affecting LV mass regression. ${ }^{4,31,32}$ Del Rizzo and associates ${ }^{20}$ found a strong and independent relationship between the iEOA and the extent of LV mass regression following AVR on 1103 patients with a porcine bioprosthesis. There was a mean decrease of LV mass of $23 \%$ in patients with an iEOA of $>0.8 \mathrm{~cm}^{2} / \mathrm{m}^{2}$ compared with $4.5 \%$ in those with an iEOA of $\leq 0.8 \mathrm{~cm}^{2} / \mathrm{m}^{2}(P=.0001) .{ }^{20}$ Hanayama and colleagues ${ }^{24}$ found no significant relationship between PPM and regression of LV hypertrophy.

With the increasing use of valve-in-valve transapical AVR for failing bioprosthetic valves, there have been an attempt at redefining the indications for ARE during conventional AVR. Worse outcomes after valve-in-valve transapical AVR have been reported in patients with small-sized $(<21 \mathrm{~mm})$ or intermediate-sized $(>21 \mathrm{~mm}$ and $<25 \mathrm{~mm}$ ) bioprostheses, those with surgical PPM, and those with postprocedural gradients of $\geq 20 \mathrm{~mm} \mathrm{Hg}$., ${ }^{2,3}$

Several investigators have investigated different ARE procedures and demonstrated relative success at the expense of increased mortality $(7.1 \%$ vs $3.5 \%){ }^{7,8,12,28,29,31}$ Patients in our study reveal that our patients were at least as complex and were in advanced New York Heart Association status. In this study, our overall early mortality is $1.7 \%$, which is in accordance with the aforementioned results. The greater mortality in ARE reported by others can be attributed to the technique.

The technique of suturing the pericardium or synthetic patch at the bottom end of the aortotomy is of paramount importance. There is naturally a weakened and thinned out area in which the mitral valve and the subaortic curtain meet between the fibrous trigones that separate it from the outside. Intraoperative subannular bleeding from disruption of this friable area following ARE is a catastrophic complication with an unknown incidence. In a retrospective review of 2366 cases of AVR from the Mayo clinic over a 9-year period, $10.5 \%$ of patients underwent posterior ARE. They reported $4.8 \%$ rate of reoperations for bleeding and operative mortality was $5.6 \% .^{15}$

Our technique of retention of a pericardial collar, at the site of enlarged ventriculo-aortic junction, and Teflonbuttressed suture avoids cut through of the periaortic tissues, thus avoided bleeding from the lower angle of aortotomy. Although the retained collar of pericardium at the ventriculo-aortic junction and Teflon-buttressed sutures predictably provided adequate hemostatic tissue support in all patients in this study, the results may be different in an older population with more friable periaortic tissues.

For repair of the aortotomy, synthetic patches of Dacron or polytetrafluoroethylene generally have been preferred whereas autologous pericardium has only been used in $11 \%$ to $27 \%$ of patients. ${ }^{11,14}$ The advantages of autologous pericardium are, its pliability, resistance to infection, and non-immunogenicity. However, with the passage of time there are concerns of fibrotic thickening, contraction, calcification, or large aneurysm formation when exposed to systemic pressure. ${ }^{9-14}$ Although the pericardial patch has been used to repair cardiac defects, its strength as an aortoplasty patch to tolerate systemic pressure remains debatable. The rate of occurrence of aneurysm of pericardial patches for enlargement of right ventricular outflow tract ranges between $6 \%$ and $25 \%$, and this seems to be related to the size of the patch or high-pressure gradient at the distal end of the patch. ${ }^{10}$

Literature documents isolated case reports of patch aneurysm, aortic dissection, paraprosthetic leakage, mitral valve insufficiency, and endocarditis following usage of pericardial patch. ${ }^{9-14}$ Glutaraldehyde-treated pericardium increases the tensile strength and reduces subsequent stretching of the patch and is thought to reduce late aneurysm formation. ${ }^{33}$ Anticalcification technology, host cell migration and proliferation, and accelerated endothelialization may be responsible for low rate of pseudoaneurysm formation. However, when the bovine pericardial patch is used for ARE, there have been sporadic reports of aneurysm/pseudoaneurysm formation of unclear etiology. ${ }^{9-14}$ To improve the strength and durability of the repair, Morisaki and colleagues ${ }^{13}$ recommended usage of a double-layered patch consisting of a bovine pericardial patch reinforcement with a HEMASHIELD patch (AMS, Cairo, Egypt).

Although large series of ARE with AVR have been reported using a variety of materials, such as autologous or xenograft pericardium or synthetic patches, reports on long-term follow-up are scant. ${ }^{12,14-16,21,23,31}$ Piehler and colleagues $^{14}$ analyzed the long-term follow-up (mean 5.4 years, max 15 years) of patients who had autologous pericardial patches inserted during AVR. Patients requiring reoperation $(\mathrm{n}=24)$ in this study demonstrated wellhealed, thickened, and calcified pericardium. Our study provides long-term data on the change of aortic root dimension at the level of sinus of Valsalva and sinotubular junction.

Kulik and colleagues ${ }^{34}$ reported their experience with 114 patients undergoing ARE (Nicks) using either a patch of synthetic material or autologous pericardium. At 10year follow-up, the actuarial survival was $69.7 \%$ and $86.4 \%$, respectively. Regarding freedom from congestive cardiac failure, data were almost similar to those 
undergoing isolated AVR. ${ }^{12,29,34}$ We have demonstrated that ARE can be performed with low mortality and without significantly increasing operative/myocardial ischemic times as observed by others. $5,6,28,29$

Because of the intrinsic gradient of any implanted stented mechanical or biological prosthesis, mild PPM is unavoidable after AVR with ARE. Further findings of our study indicate that this procedure was not associated with paravalvular leak, significant mitral regurgitation, or aneurysmal dilatation (Figure 3,A-P). The stability of aortic diameters with time was confirmed by echocardiography and angiography. Although the patch is inserted in a highpressure environment, autogenic pericardial tissue did not calcify or dilate because of limited size, shrinkage with time, thus serving a valid alternative to synthetic material.

\section{CONCLUSIONS}

Our study demonstrates that surgical ARE is a safe adjunct to AVR, allows larger prosthesis to be inserted, minimizes predictable PPM, does not interfere with the function of the mitral valve, and provides adequate relief of left ventricular outflow obstruction without increased risk of mortality and perioperative bleeding.

Retention of a pericardial collar at the ventriculo-aortic junction and Teflon-buttressed sutures avoids cut through of the friable aortic tissues. We also confirm that untreated autologous pericardium is a versatile material for aortoplasty because it allows adequate hemostatic sutures, is strong enough to hold stitches, and does not dilate with time. Surgeons should carefully consider patient age, body surface area, and internal orifice of their chosen valve model and size at the time of AVR.

\section{Conflict of Interest Statement}

The authors reported no conflicts of interest.

The Journal policy requires editors and reviewers to disclose conflicts of interest and to decline handling or reviewing manuscripts for which they may have a conflict of interest. The editors and reviewers of this article have no conflicts of interest.

\section{References}

1. Rahimtoola SH. The problem of valve prosthesis-patient mismatch. Circulation. 1978;58:20-4.

2. Dvir D, Webb JG, Bleiziffer S, Pasic M, Waksman R, Kodali S, et al; Valve-inValve International Data Registry Investigators. Transcatheter aortic valve implantation in failed bioprosthetic surgical valves. JAMA. 2014;312:162-70.

3. Webb JG, Mack MJ, White JM, Dvir D, Blanke P, Herrmann HC, et al. Transcatheter aortic valve implantation within degenerated aortic surgical bioprostheses: PARTNER 2 valve in-valve registry. J Am Coll Cardiol. 2017;69:2253-62.

4. Pibarot P, Dumesnil JG, Cartier PC, Metras J, Lemieux MD. Patient-prosthesis mismatch can be predicted at the time of operation. Ann Thorac Surg. 2001; 71:S265-8

5. Blais C, Dumesnil JG, Baillot R, Simard S, Doyle D, Pibarot P. Impact of valve prosthesis-patient mismatch on short-term mortality after aortic valve replacement. Circulation. 2003;108:983-8.

6. Head SJ, Mokhles MM, Osnabrugge RL, Pibarot P, Mack MJ, Takkenberg JJ, et al. The impact of prosthesis-patient mismatch on long-term survival after aortic valve replacement: a systematic review and meta-analysis of 34 observational studies comprising 27186 patients with 133141 patient-years. Eur Heart J. 2012;33:1518-29.

7. Nicks R, Cartmill T, Bernstein L. Hypoplasia of the aortic root. The problem of aortic valve replacement. Thorax. 1970;25:339-46.

8. Manouguian S, Seybold-Epting W. Patch enlargement of the aortic valve ring by extending the aortic incision into the anterior mitral leaflet. New operative technique. J Thorac Cardiovasc Surg. 1979;78:402-12.

9. Kinsley RH. The narrow aortic annulus. A technique for inserting a larger prosthesis. Am Heart J. 1977;93:759-61.

10. Brinster DR, Patel JA. The use of CorMatrix extracellular matrix for aortic root enlargement. J Cardiothorac Surg. 2014;19:178.

11. Dalichau H, Hannekum A, Niehues B, Irion A, Herse B. Hemodynamic and angiographic late results following enlargement of narrow aortic root using autologous pericardium in prosthetic aortic valve replacement. J Thorac Cardiovasc Surg. 1985;33:288-95.

12. Borracci RA, Rubio M, Camargo RLP, Archer M, Ingino C. Aortic root enlargement of a small annulus using the Nick's technique during aortic valve replacement. Rev Argent Cardiol. 2014;82:504-7.

13. Morisaki A, Kato Y, Motoki M, Takahashi Y, Nishimura S, Shibata T. Rupture of equine pericardial aortic-root patch after aortic valve replacement with aortic annulus enlargement: a case report. J Cardiothorac Surg. 2014;9:109.

14. Piehler JM, Danielson GK, Pluth JR, Orszulak TA, Puga FJ, Schaff HV. Enlargement of the aortic root or anulus with autogenous pericardial patch during aortic valve replacement. J Thorac Cardiovasc Surg. 1983;86:350-8.

15. Dhareshwar J, Sundt TM III, Dearani JA, Schaff HV, Cook DJ, Orszulak TA Aortic root enlargement: what are the operative risks? J Thorac Cardiovasc Surg. 2007;134:916-24.

16. Celiento M, Saccocci M, De Martino A, Nardi C, Faggioni L, Milano AD Bortolotti U. Stability of aortic annulus enlargement during aortic valve replacement using a bovine pericardial patch: an 18-year clinical, echocardiographic, and angio-computed tomographic follow-up. J Thorac Cardiovasc Surg. 2014; 147:977-83

17. Chowdhury UK, Sankhyan LK, George N, Singh S, Gayatri S, Avneesh S, et al Posterior aortic root enlargement (Nick's procedure), mechanical aortic valve replacement and patch closure of the sacciform proximal aortic arch aneurysm by "open" technique without circulatory arrest: a video presentation. Int Med. 2020;2:92.

18. STS Adult Cardiac Database Definition of terms (2.41). Chicago, IL: Society of Thoracic Surgeons; 2002. Available at: http://www.sts.org/file/CoreDel241 Book.pdf.2002.

19. Chowdhury UK, Chauhan AS, Hasija S, Jena JK, Sankhyan LK, Phulware R. Aortic root enlargement and aortic valve replacement for calcified supravalvular and valvular aortic stenosis in homozygous familial hypercholesterolemia: a case report. World J Pediatr Congenit Heart Surg. 2020;11:NP221-5.

20. Del Rizzo DF, Abdoh A, Cartier P, Doty D, Westaby S. Factors affecting left ventricular mass regression after the aortic valve replacement with stentless valves. Semin Thorac Cardiovasc Surg. 1999;11:114-20.

21. Rocha RV, Manlhiot C, Feindel CM, Yau TM, Mueller B, David TE, Ouzounian M. Surgical enlargement of the aortic root does not increase the operative risk of aortic valve replacement. Circulation. 2018;137:1585-94.

22. Tasca G, Brunelli F, Cirillo M, DallaTomba M, Mhagna Z, Troise G, et al. Impac of valve prosthesis-patient mismatch on left ventricular mass regression following aortic valve replacement. Ann Thorac Surg. 2005;79:505-10.

23. Yu W, Tam DY, Rocha RV, Makhdoum A, Ouzounian M, Fremes SE. Aortic root enlargement in safe and reduces the incidence of patient-prosthesis mismatch: a meta-analysis of early and late outcomes. Can J Cardiol. 2019;35:782-90.

24. Hanayama N, Christakis GT, Mallidi HR, Joyner CD, Fremes SE, Morgan CD et al. Patient prosthesis mismatch is rare after aortic valve replacement: valve size may be irrelevant. Ann Thorac Surg. 2002;73:1822-9.

25. Medalion B, Blackstone EH, Lytle BW, White J, Arnold JH, Cosgrove DM Aortic valve replacement: is valve size important? J Thorac Cardiovasc Surg. 2000;119:963-74.

26. Beckmann E, Martens A, Alhadi F, Hoeffler K, Umminger J, Kaufeld T, et al Aortic valve replacement with sutureless prosthesis; better than root enlargemen to avoid patient-prosthesis mismatch? Interact Cardiovasc Thorac Surg. 2016; 22:744-9.

27. Kratz JM, Sade RM, Crawford FA Jr, Crumbley AJ III, Stroud MR. The risk of small St Jude aortic valve prostheses. Ann Thorac Surg. 1994;57:1114-9.

28. Sommers KE, David TE. Aortic valve replacement with patch enlargement of the aortic annulus. Ann Thorac Surg. 1997;63(suppl):S1608-12. 
29. Carrier M, Pellerin M, Perrault LP, Hebert Y, Page P, Cartier R, et al. Experience with the 19-mm Carpentier-Edwards pericardial bioprosthesis in the elderly. Ann Thorac Surg. 2001;71(suppl):S249-52.

30. Stenseth JH, Danielson GK, McGoon DC. Pericardial patch enlargement of the aortic outflow tract. J Thorac Cardiovasc Surg. 1971;62:442-8.

31. Tam DY, Dharma C, Rocha RV, Ouzounian M, Wijeysundera HC, Austin PC, et al. Early and late outcomes following aortic root enlargement: a multicentre propensity score-matched cohort analysis. J Thorac Cardiovasc Surg. September 28, 2019 [Epub ahead of print].

32. Verdecchia P, Reboldi GP, Schillaci G, Borgioni C, Ciucci A, Telera MP, et al Circulating insulin and insulin growth factor-1 are independent determinants of left ventricular mass and geometry in essential hypertension. Circulation. 1999;100:1802-7.
33. Haluck RS, Richembacker WE, Myers JL, Miller CA, Wise RK, Waldhausen JA Pericardium as a thoracic aortic patch: glutaraldehyde-fixed and fresh autologous pericardium. J Surg Res. 1980;48:611-4.

34. Kulik A, Burwash IG, Kapila V, Mesana TG, Ruel M. Long-term outcomes after valve replacement for low-gradient aortic stenosis: impact of prosthesis-patient mismatch. Circulation. 2006;114(1 suppl):I553-8.

Key Words: aortic valve replacement, aortic root enlargement, Nicks' procedure, periprosthetic leakage, pericardial patch aneurysm, prosthesis-patient mismatch, indexed aortic effective orifice area 